\title{
KAJIAN DAMPAK KEPEMIMPINAN DAN BUDAYA ORGANISASI TERHADAP KNOWLEDGE SHARING DI PERUSAHAAN DAERAH AIR MINUM PULAU LOMBOK
}

\author{
Hermanto $^{1}$, Agusdin ${ }^{2}$, Surati ${ }^{3}$, Ni Ketut Surasni ${ }^{4}$ \\ 1,2,3,4Fakultas Ekonomi dan Bisnis, Universitas Mataram \\ 1E-mail: hermanto2307@gmail.com \\ 2E-mail:dragusdin@gmail.com \\ 3E-mail:drsurati2013@gmail.com \\ 4E-mail:surasni12@gmail.com
}

\begin{abstract}
ARTICLE INFO
Keywords :

Leadership, Organizational Culture, Knowledge Sharing, Partial Least Square, Organizational Performance
\end{abstract}

\section{Kata Kunci :}

Kepemimpinan, Budaya Organisasi, Knowledge Sharing, Partial Least Square, Kinerja Organisasi

How to cite :

Hermanto., Agusdin., Surati., Surasni, Ni Ketut., (2020). Kajian Dampak Kepemimpinan Dan Budaya Organisasi Terhadap Knowledge Sharing Di Perusahaan Daerah Air Minum Pulau Lombok, 9(2), 198211

DOI :

http://dx.doi.org/10.29303/jmm.v9i2.548

$\begin{array}{ll}\text { Dikumpulkan } & : 10 \text { Mei } 2020 \\ \text { Direvisi } & : 17 \text { Juni } 2020 \\ \text { Dipublikasi } & : 02 \text { Juli } 2020\end{array}$

Dipublikasi : :02 Juli 2020

\section{ABSTRACT}

The purpose of this study is to examine and to explain the direct influence of leadership and organizational culture on knowledge sharing that could theoretically influence PDAMs throughout Lombok Island. This research uses a quantitative approach and data collection by survey method with the data analysis method used is partial least square. The results showed that leadership and organizational culture had a positive and significant direct effect on the knowledge sharing process based on indicators of socialization, externalization, combination and internalization. The limitation of this research lies in the limited space only in the Lombok Island PDAM environment which consists of 4 PDAMs so that a more extensive study is needed to strengthen the research results. In addition it is necessary to consider using other variables as enablers of knowledge sharing.

Tujuan penelitian ini adalah menguji dan menjelaskan pengaruh langsung kepemimpinan dan budaya organisasi terhadap knowledge sharing yang secara teori bisa berpengaruh di PDAM sePulau Lombok. Penelitian ini menggunakan pendekatan kuantitatif dan pengumpulan data dengan metode survey dengan metode analisis data yang digunakan adalah partial least square. Hasil penelitian menunjukkan bahwa kepemimpinan dan budaya organisasi memiliki pengaruh langsung positif dan signifikan terhadap proses knowledge sharing berdasarkan indikator socialization, externalization, combination dan internalization. Keterbatasan penelitian ini terletak pada ruang yang terbatas hanya di lingkungan PDAM Pulau Lombok yang terdiri dari 4 PDAM sehingga diperlukan kajian yang lebih luas untuk memperkuat hasil 


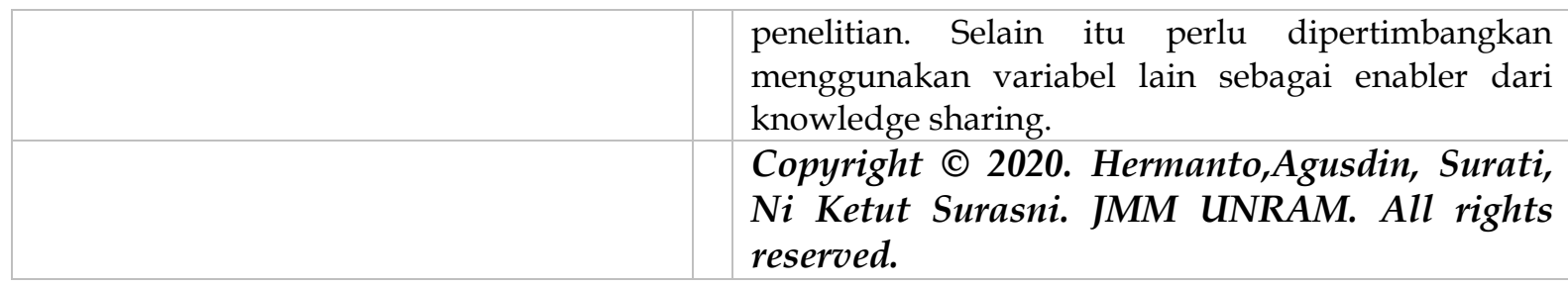

\section{PENDAHULUAN}

Masalah rendahnya kinerja beberapa PDAM di Nusa Tenggara Barat di tengarai karena persoalan lama dan belum diatasi sepenuhnya terkait rasio karyawan dengan jumlah pelanggan masih cukup tinggi, berkisar antara 122 sampai 264 pelanggan per karyawan, yang mencerminkan tingkat efisiensi rendah dalam penggunaan sumberdaya manusia. Dari sisi struktur tenaga kerja berdasarkan tingkat pendidikan menunjukkan bahwa tingkat pendidikan SMA atau sederajat merupakan mayoritas karyawan di masingmasing PDAM. Sementara kebijakan penganggaran perusahaan belum mendukung sepenuhnya peningkatan kualitas sumberdaya manusia melalui program-program pendidikan dan pelatihan.

Untuk menjawab permasalahan yang dihadapi manajemen PDAM, maka peran pengetahuan sangat penting karena merupakan intangible resource perusahaan yang bisa mempertahankan keunggulan bersaing (competitive advantage) sepanjang memiliki sifatsifat VRIO (valuable, rare, imperfect imitability, dan organized to capture value) (Barney, 1991). Dari aset intangible tersebut, knowledge diketahui secara luas sebagai aset organisasi paling penting untuk menciptakan value dan keunggulan kompetitif berkelanjutan (Nonaka, 2006; Choi et al, 2008; Yang et al., 2009). Knowledge bukan data atau informasi, melainkan kombinasi data dan informasi, ditambahkan opini pakar, keahlian, dan pengalaman menghasilkan aset berharga yang membantu pengambilan keputusan (Awad \& Ghaziri, 2004). Leibold et al. (2005) mengemukakan bahwa perubahan lingkungan bisnis yang cepat dalam jangka panjang telah membawa konsekuensi pada pilihan strategi yang dinamis dan kuat, dimana kepastian secara ekonomi adalah ketidakpastian itu sendiri dan hanya knowledge (pengetahuan) yang dapat diandalkan sebagai sumber keunggulan bersaing (Nonaka, HBR 2006).

Peran strategis knowledge bagi organisasi menyebabkan keberhasilan perusahaan banyak ditentukan oleh kemampuan mengelola pengetahuan itu sendiri dan bermuara pada kualitas pengetahuan yang dihasilkan serta efektivitas setiap tindakan dalam hal implementasi knowledge tersebut. Sejumlah kajian telah memperlihatkan proses KM terdiri dari acquisition, conversion, creation, storage, transfer, dissemination, internalization, externalization, dan application (Nonaka \& Takeuchi, 1995; Gold et al., 2001, Alavi \& Leidner, 2001). Salah satu konsep knowledge management yang banyak digunakan dalam berbagai kajian adalah SECI (Socialization, Externalization, Combination, dan Internalization) yang dikemukakan oleh Nonaka \& Takeuchi (1995) karena konsep ini bukan hanya menjelaskan tentang knowledge creation tapi juga berkenaan dengan hal paling penting dalam keseluruhan proses yakni knowledge sharing (transfer).

Kajian-kajian lain juga memperlihatkan kontribusi KM terhadap kinerja atau efektivitas organisasi. Jiang \& Yu (2009) menunjukkan pengaruh signifikan antara knowledge creation dan sharing dengan peningkatan kinerja dan inovasi organisasi. Secara lebih spesifik Sabherwal \& Beccera-Fernandez (2003), Tseng (2010), dan Tsai \& Li (2007) melakukan eksplorasi terhadap pengaruh masing-masing indikator SECI terhadap berbagai unsur pembentuk kinerja organisasi (financial dan non-financial). 
Di setiap organisasi, pemimpin harus memperlihatkan contoh kepada para bawahan sehingga nampak bahwa kepemimpinannya memberikan dampak langsung terhadap sikap seluruh elemen organisasi dalam proses dan praktik knowledge sharing. Jika knowledge sharing tidak bisa menembus semua jenjang organisasi, dan seharusnya dimulai dari manajemen puncak, maka program-program knowledge sharing cenderung tidak efektif (De Tienne et al., 2004). Lebih khusus lagi Politis (2001); Crawford (2005); Singh (2008) dan Yueh et al. (2010) menemukan bahwa kepemimpinan berpengaruh langsung terhadap knowledge sharing, juga bisa mempengaruhi kinerja karyawan, dan pada akhirnya terhadap kinerja organisasi secara keseluruhan seperti dibuktikan oleh beberapa peniliti (Kennedy \& Anderson, 2002; Bass et al., 2003; Xenikou \& Simosi, 2006).

Dari sisi iklim organisasi kajian Davenport et al. (1998), Alavi et al. (2005), Rai (2011) menemukan bahwa nilai-nilai dalam organisasi sangat penting untuk memfasilitasi efektivitas proses KM, khususnya knowledge sharing dimana organisasi yang lebih terbuka dengan orientasi nilai memiliki kecenderungan perilaku knowledge yang konstruktif, seperti adanya wawasan untuk selalu berbagi pengetahuan di kalangan anggota organisasi (Gold et al., 2001). Nilai-nilai tersebut merupakan bagian dari kapabilitas infrastruktur knowledge perusahaan yang mempengaruhi kemampuan inovasi dan adaptasi dengan perubahan lingkungan serta mampu menjawab perubahan pasar.

Berkaitan dengan uraian tersebut maka penelitian ini akan mengkaji keterkaitan langsung antara knowledge management enablers (kepemimpinan dan budaya organisasi) dengan knowledge sharing pada PDAM di Pulau Lombok. Hal ini disebabkan oleh beberapa alasan: (1) Di tingkat nasional maupun daerah, kinerja PDAM masih kurang baik. Hal ini ditengarai sebagai akibat dari belum tersedianya sumber daya manusia yang handal dan lemahnya manajemen; (2) Belum ada penelitian yang mengkaji secara spesifik aspek-aspek knowledge management di lingkungan perusahaan milik daerah (PDAM). Kompleksitas persoalan organisasi ada pada kombinasi beberapa variabel internal yang sangat mempengaruhi pengembangannya, termasuk terkait dengan persoalan kuantitas dan kualitas sumber daya manusia di dalamnya. Pada peneitian ini ada 3 variabel internal organisasi yang akan dijadikan kajian, yakni kepemimpinan (leadership), budaya organisasi (organizational culture) dan berbagi pengretahuan (knowledge sharing). Untuk pembahasan selanjutnya terminologi knolwdge sharing akan tetap diggunakan agar mudah memahami konteks yang dibahas.

Berdasarkan uraian di atas, maka dapat dirumuskan tujuan penelitian bahwa berbagai teori kepemimpinan dikemukakan oleh para ahli dengan perspektif berbeda satu sama lain. Berdasarkan hasil penelitian, masing-masing teori memberikan pengaruh yang tidak sama terhadap proses knowledge sharing sebagai akibat dari waktu pelaksanaan dan lingkup penelitian. Selain kepemimpinan, faktor-faktor budaya organisasi sebagai atribut organisasi, baik yang bersifat tangible maupun intangible, mempengaruhi knowledge sharing dalam berbagai dimensi. Secara lebih spesifik tujuan peneilitian ini akan mendeskripsikan peran kepemimpinan terhadap proses knowledge sharing di lingkungan PDAM, mengingat bahwa sampai penelitian ini dilaksanakan badan hukum perusahaan masih Perusahaan Daerah dimana mekanisme pemilihan direksi dan nuansa kepemimpinan masih dipengaruhi oleh peran kepala daerah. Tujuan penelitian lain adalah bagaimana budaya organisasi di perusahaan daerah bisa menjadi katalisator proses knowledge sharing di kalangan internal organisasi maupun antar organisasi. 


\section{KAJIAN TEORITIS}

Leadership melekat pada individu dalam organisasi untuk menentukan efektivitas implementasi knowledge management (Liebowitz, 1999; Bishop et al., 2008), baik selaku top management (Nonaka et al., 2000; De Tienne et al., 2004) yang memberikan contoh kepada seluruh jenjang dalam organisasi, maupun middle management yang menjembatani pola pikir top management dengan pekerja di tingkat bawah (front-line employee). Lebih jauh ditegaskan bahwa hambatan budaya yang dialami dalam proses knowledge management dapat diatasi dengan peran leadership yang jelas dalam organisasi, sebab di dalamnya orang-orang didorong untuk mengkomuniasikan dan membagi pengetahuan yang dimiliki (Nonaka \& Takeuchi, 1995). Keunggulan bersaing perusahaan terletak pada keunikan berbagai sumber daya yang dimiliki dan ketidakmampuan pesaing untuk menirunya. Nilai sumber daya tertentu bagi perusahaan akan semakin tinggi karena keberadaan sumber daya lainnya dan adanya hubungan satu sama lain (Collis \& Montgomery, 2008). Budaya organisasi sebagai keyakinan, nilai, norma dan sikap yang mengatur individu bertindak dan berlaku dalam organisasi, adalah salah satu sumber daya nirwujud (intangible resources) yang dimiliki oleh perusahaan (Holsapple \& Joshi, 2001; Davenport et al., 1998; Grover \& Davenport, 2001; Gold et al., 2001; Chuang, 2004). Knowledge-based view melihat perusahaan sebagai sekumpulan aset pengetahuan (knowledge assets), dan berperan menciptakan dan menggunakan aset tersebut untuk menghasilkan nilai (Grant, 1996). Strategy organisasi merupakan sarana untuk menciptakan dan memanfaatkan aset nirwujud tersebut. Knowledge management bisa memberikan warna dalam memaknai knowledge, koordinasi terhadap transfer knowledge yang penting serta sebagai acuan dalam eksploitasi knowledge yang dapat meningkatkan efektivitas organisasi.

Leibold (2005) mengemukakan bahwa era industri (industrial age) bisnis telah bergeser ke era pengetahuan (knowledge age) dalam berbagai aspek pengelolaan organisasi perusahaan, seperti penggunaan sumber daya sangat tergantung pada tangible assets berupa material dan modal finansial, telah ditinggalkan karena peran kepemilikan dan penguasaan pengetahuan (knowledge) dan modal intelektual (intellectual capital). Demikian halnya dengan pengembangan pengetahuan sumber daya manusia menghasilkan tenaga kerja dengan keterampilan sangat khusus berubah menjadi tenaga kerja dengan pengetahuan lintas disiplin. Knowledge management pada dasarnya merupakan suatu proses atau siklus dan operasional knowledge, dan dilihat sebagai bentuk koordinasi terstruktur untuk mengelola pengetahuan secara efektif dalam organisasi (Gold et al., 2001). Prosesproses tersebut sering terjadi bersamaan dan tidak selalu dengan urutan yang sama (Alavi \& Leidner (2001), Awad dan Ghaziri (2004) mengatakan bahwa proses knowledge management atau knowledge management life cycle juga terdiri dari empat tahapan mulai dari knowledge capturing, organizing, refining, dan knowledge transfer. Nonaka \& Takeuchi (1995) mengemukakan fase proses penciptaan knowledge organisasi dengan menyertakan dimensi waktu ke dalam model konversi knolwedge SECI (Socialization, Externalization, Combination, dan Internalization). SECI menggambarkan model dinamis penciptaan pengetahuan dalam organisasi yang disadarkan pada asumsi bahwa pengetahuan manusia diciptakan dan dikembangkan melalui interaksi sosial antara tacit knowledge dan explicit knowledge. Ke lima fase tersebut adalah: 1) sharing tacit knowledge; 2) creating concepts: 3) justifying concepts; 4) building an archetype; dan 5) cross-leveling knowledge.

Melalui knowledge sharing, individu berbagi opini, pengalaman dan informasi organisasional dalam organisasi. Knowledge sharing yang terjadi di antara individu dapat terjadi dengan 2 cara, yakni secara explicit (terdokumentasi) yakni pengetahuan yang 
mudah berpindah dan dipahami, serta secara tacit yang bersifat lebih spesifik di antara sesame individu (Bartol \& Srivastava, 2002).

\section{METODE PENELITIAN}

Secara metodologi, penelitian ini menggunakan paradigma positivis yaitu pendekatan penelitian kuantitatif dengan melihat hubungan kausalitas antara variabel eksogen dengan variable endogen. Penelitian akan dilakukan pada 4 PDAM Pulau Lombok. Populasinya adalah seluruh seluruh karyawan perusahaan yang aktif yang memegang jabatan dari kepala bagian sampai dengan kepala seksi, berjumlah 225 orang. Sampel responden sebanyak 30\% (68 orang) ditentukan dengan metode purposive sampling.

Rancangan teknik analisis data yang digunakan dalam penelitian ini adalah analisis Statistik Deskriptif digunakan untuk mendeskripsikan responden penelitian (usia, jenis kelamin, pendidikan, lama dalam jabatan saat ini, lama bekerja di PDAM) dan variabel penelitian. Data yang dikumpulkan kemudian diedit dan ditabulasikan dalam tabel dan dilakukan pembahasan secara deskriptif. Analisis Statistik Inferensial Penggunaan metode statistik inferensial adalah untuk menguji model empiris dan hipotesis yang diangkat dalam penelitian ini. Analisis inferensi yang dilakukan menggunakan analisis PLS (Partial Least Square) (Ghozali, 2011).

\section{HASIL DAN PEMBAHASAN}

Gambaran persepsi responden terhadap lima indikator kepemimpinan ditunjukkan dengan gambar berikut. Deskripsi persepsi responden terhadap indikator variabel bukan untuk menggambarkan kekuatan hubungan indikator dengan variabel laten. Kepemimpinan berkenaan dengan proses bagaimana seorang pemimpin bisa menjadi inspirasi bagi semua pengikut untuk mencapai visi melalui kepercayaan dan hormat yang diberikan para pengikut karena memiliki komitmen yang kuat. Hal ini akan tercapai dengan penciptaan lingkungan kerja yang kondusif sehingga semua unsur dalam organisasi secara sukarela bergerak bersama dan termotivasi untuk mencapai tujuan yang telah ditetapkan.

Persepsi responden tentang kelima indikator kepemimpinan diperlihatkan oleh gambar berikut.

Gambar 5.1. Rerata Persepsi Responden Terhadap Kepemimpinan

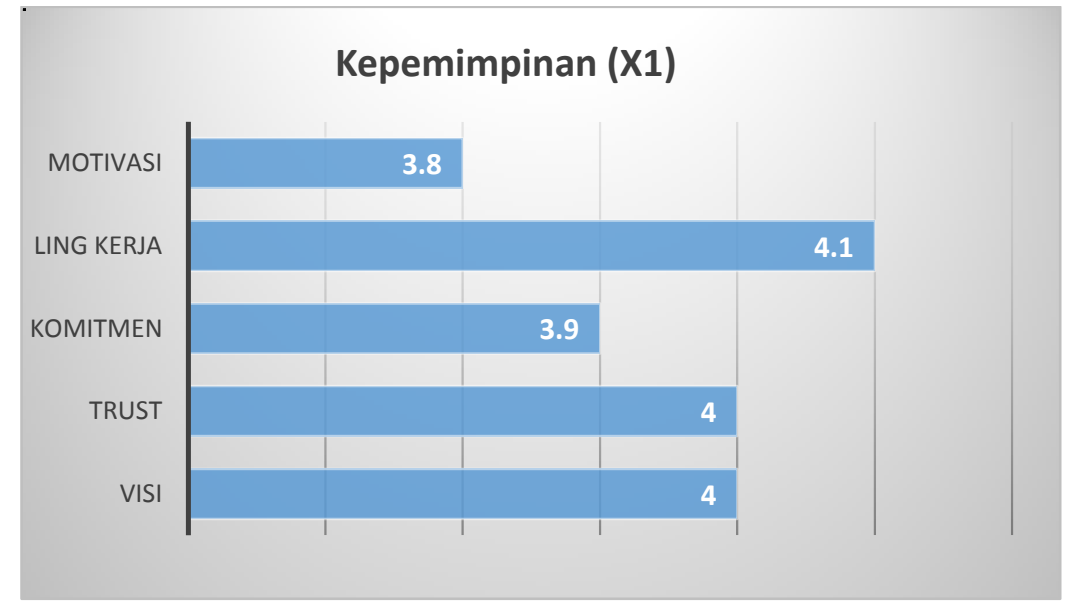

Sumber : Lampiran 
Pemimpin memiliki power untuk mempengaruhi kemana arah pengembangan pengetahuan dalam sebuah organisasi. Lima indikator kepemimpinan di atas memperlihatkan bagaimana peran kepemimpinan terhadap proses knowledge sharing dalam organisasi berjalan. Gambar di atas juga menunjukkan responden memiliki persepsi bahwa lingkungan kerja, trust (kepercayaan) dan visi memberikan kontribusi lebih besar pada pengaruh kepemimpinan terhadap proses knowledge sharing dalam organisasi PDAM di Pulau Lombok dibandingkan dengan 2 indikator motivasi dan komitmen. Hal ini merupakan indikasi bahwa faktor kepemimpinan di lingkungan PDAM Pulau Lombok telah menunjukkan kepemimpinan visioner sehingga meninmbulkan kepercayaan di kalangan staf yang ada. Muara dari kepemimpinan visioner adalah terciptanya lingkungan kerja (fisik dan non fisik) kondusif sebagai basis tumbuhnya budaya organisasi positif. Indikasi ini sejalan dengan temuan Nonaka \& Takeuchi (1995) bahwa hambatan-hambatan lain dalam organisasi dalam proses knowledge sharing dapat diatasi dengan peran leadership dimana orang-orang didorong untuk mengkomuniasikan dan membagi pengetahuan yang dimiliki.

Budaya organisasi merupakan keyakinan, nilai, norma dan sikap yang mengatur individu bertindak dan berlaku dalam organisasi (adaptability, involvement, consistency, dan agreement), adalah salah satu sumber daya nirwujud (intangible resources) yang dimiliki oleh perusahaan untuk mencapai keunggulan bersaing ketika bernilai, langka dan sulit ditiru. Budaya organisasi, seperti dimensi organisasi lainnya, membentuk dan mengawasi perilaku individu dalam organisasi, serta mempengaruhi bagaimana orang-orang dalam organisasi menyesuaikan diri sesuai dinamika lingkungan di mana organisasi berada. Setiap organisasi memiliki budaya masing-masing untuk dijalankan sehingga berpengaruh terhadap bagaimana individu bertindak dan berkomunikasi serta mempengaruhi cara mengelola pengetahuan.

Gambar 5.2. Deskripsi Persepsi Responden Terhadap Variabel Budaya Organisasi $\left(\mathrm{X}_{2}\right)$

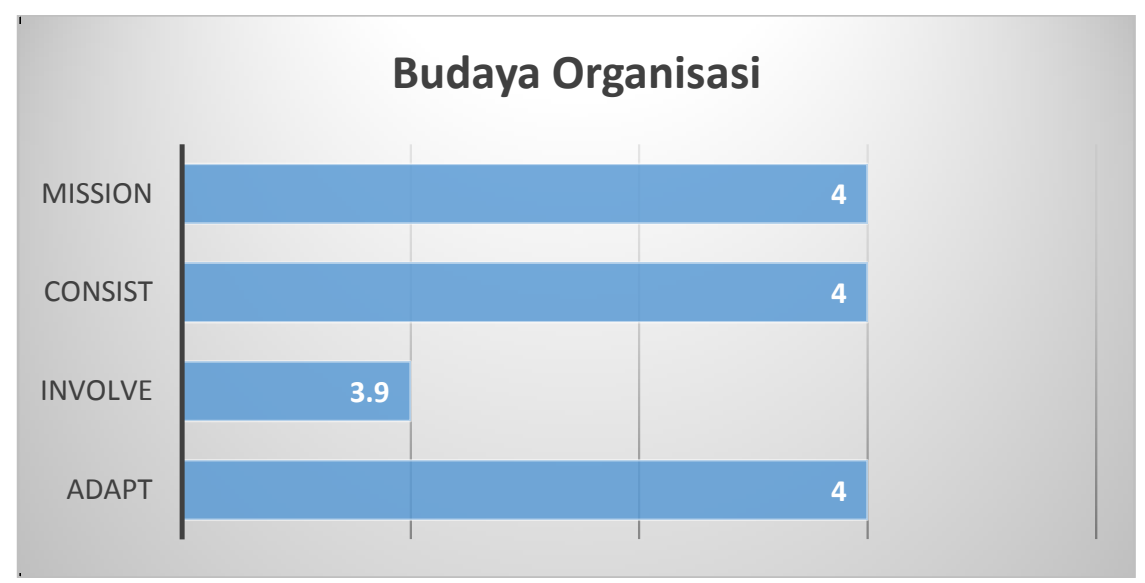

Sumber : Lampiran

Secara konseptual, indikator involvement dan consistency menentukan seberapa intens perhatian manajemen terhadap isu-isu internal (internal focus) perusahaan, sementara indikator adaptability dan mission menunjukkan tingkat kepedulian terhadap dinamika eksternal perusahaan (external focus). Berdasarkan jawaban responden yang diperlihatkan pada gambar di atas bahwa perbandingan total skor 2 indikator internal focus (consistency \& involvement) sebesar 7.9 dan skor 2 indikator external focus (adaptability \& mission) sebesar 8.0. Perbandingan nilai rerata keduanya menunjukkan bahwa manajemen perusahaan menerapkan kebijakan yang cenderung lebih memperhatikan hal-hal yang berkaitan dengan proses eksternal organisasi, bagaimana perusahaan selalu bisa menyesuaikan diri dengan dinamika eksternal dan pencapaian tujuan-tujuan perusahaan. 
Kombinasi keempat indikator di atas dapat juga dilihat secara vertikal, yakni indikator adaptability dan involvement secara bersamaan menentukan tingkat flexibility, dan indikator mission dan consistency menentukan tingkat stability. Total skor yang diperoleh menunjukkan bahwa jumlah skor indikator pembentuk flexibility lebih rendah (7.9). Temuan ini merupakan indikasi bahwa responden menyatakan manajemen perusahaan cenderung untuk menjalankan kebijakan bagaimana menjaga keseimbangan antara memelihara stabilitas perusahaan di tengah-tengah tuntutan-tuntutan persaingan dalam industri. Selisih 0,1 rerata tanggapan responden terhadap indikator ekternal dan internal merupakan perbedaan yang sangat tipis antara keduanya. Hal ini menunjukkan bahwa budaya organisasi yang dihasilkan dari karakter kepemimpinan tersebut masih seimbang antara menciptakan kondisi organisasi stabil dan kondusif dengan selalu mempertimbangkan kepentingan berbagai kelompok external stakeholder dalam setiap keputusan manajemen PDAM. Dengan kata lain dapat dinyatakan bahwa implemetasi fungsi ekonomi dan sosial PDAM terwujud dalam keseimbangan nilai-nilai stabilitas dan fleksibilitas perusaha perusahaan.

Dixon (1999) menyatakan bahwa berbagi pengetahuan dimulai dengan setiap tim melakukan sesuatu yang bisa dimanfaatkan oleh orang lain dalam organisasi dan tim sendiri menggunakan apa yang orang lain ketahui. Demikian juga, King (2001) sependapat bahwa berbagi pengetahuan merupakan budaya yang berkontribusi pada keberhasilan manajemen strategy pengetahuan sehingga beberapa ahli mencoba untuk memperjelas perlunya berbagi pengetahuan dalam sebuah organisasi. Hong dan Kuo (1999) menyarankan bahwa belajar melalui berbagi menjadi inti operasional manajemen pengetahuan. Dengan demikian, organisasi dapat mengembangkan karakteristik penting Learning Organization jika telah menempatkan penekanan besar pada proses pembelajaran melalui berbagi.

Gambar 5.3. Deskripsi Persepsi Responden Terhadap Variabel Knowledge Sharing $\left(\mathrm{Y}_{1}\right)$

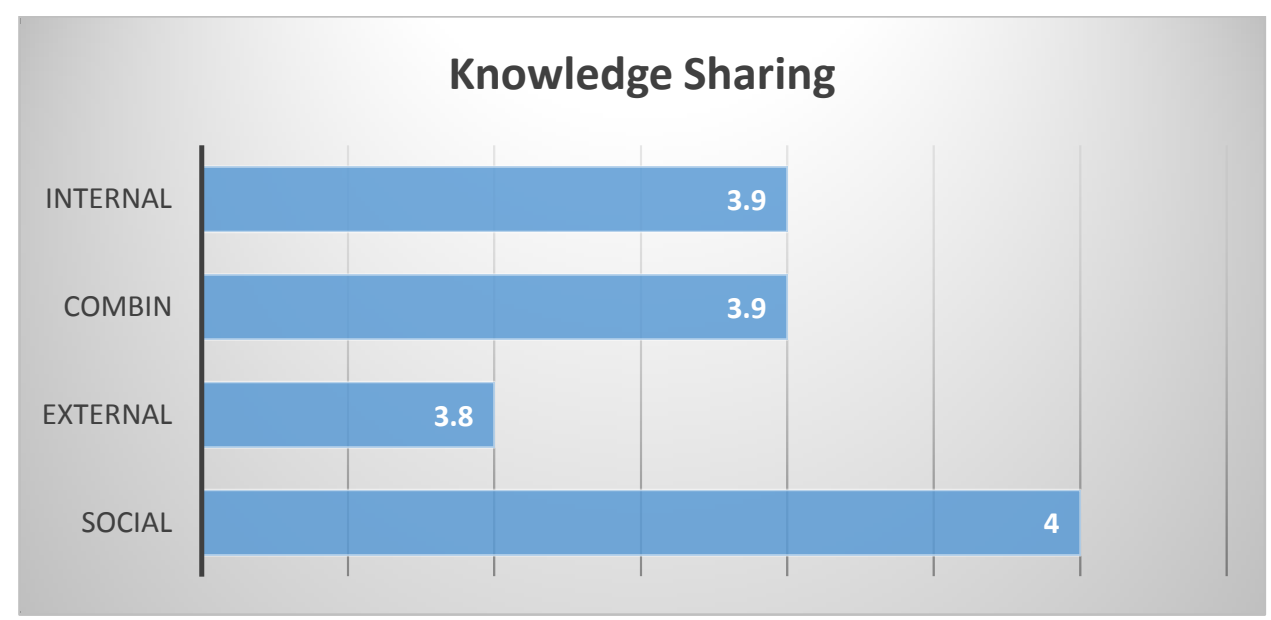

Sumber : Lampiran

Nonaka \& Takeuchi (1995) mengemukakan empat fase proses penciptaan knowledge organisasi dengan menyertakan dimensi waktu ke dalam model konversi knolwedge yakni SECI (Socialization, Externalization, Combination, dan Internalization). SECI menggambarkan model dinamis penciptaan pengetahuan dalam organisasi yang didasarkan pada asumsi bahwa pengetahuan manusia diciptakan dan dikembangkan melalui interaksi sosial antara tacit knowledge dan explicit knowledge. Dari keempat proses di atas, socialization (merupakan transfer pengetahuan di lingkungan internal organisasi) merupakan proses terkuat dibandingkan lainnya dalam arti bahwa proses memperlakukan tacit knowledge sebagai pengalaman berbagi bersama dalam organisasi merupakan hal paling strategis. 
Sehubungan dengan hal tersebut maka peran leadership merupakan salah satu faktor kunci keberhasilan (enablers atau drivers) penerapan knowledge sharing dalam suatu organisasi (Holsapple \& Joshi, 2000). Dengan power yang dimiliki, seorang pemimpin dapat bertidak selaku motivator atau contoh bagaimana seharusnya melakukan knowledge sharing. Berikutnya Singh (2008) mengatakan bahwa manajemen sebaiknya mengutamakan peran leadership dalam knowledge sharing sehingga memberikan dampak kepada penyebaran pengetahuan secara menyeluruh dalam organisasi. Jika pemimpin memberikan contoh bagaimana seharusnya knowledge management dikelola, maka semua organ lain dalam organisasi akan mengikuti. Kalangan praktisi dan akademisi sepakat bahwa leadership sangat berperan dalam penciptaan dan pengelolaan pengetahuan dalam organisasi, sehingga keunggulan bersaing sebagai tujuan organisasi knowledge management dapat dicapai melalui implementasi leadership.

\subsection{Uji Validitas \& Reliabilitas}

Convergent validity digunakan untuk mengukur dalam menentukan apakah setiap indikator yang diestimasi telah valid mengukur dimensi dari konsep yang diukur. Ukuran refleksif individu dikatakan tinggi jika berkorelasi lebih dari 0.70 dengan konstruk yang ingin diukur. Namun demikian, untuk penelitian tahap awal dari pengembangan skala pengukuran nilai loading 0.50 sampai 0.60 dianggap cukup (Chin, 1998 dalam Ghozali 2011, p. 25). Pengukuran lain dapat juga menggunakan besaran nilai AVE (Fornell \& Larcker, 1981) dengan besaran nilai yang dapat diterima harus $>0.50$.

Hasil uji validitas menunjukkan bahwa nilai loading factor indikator refleksi yang menggambarkan variabel kepemimpinan memperlihatkan bahwa aspek trust merupakan indikator terkuat (0.865) yang bisa menggambarkan kepemimpinan manajemen perusahaan. Dari aspek nilai AVE, seluruh variabel penelitian memiliki nilai lebih besar dari 0.50 artinya instrumen penelitian yang digunakan untuk mengukur variabel kepemimpinan memenuhi kriteria validitas diskriminan. Discriminant validity merupakan pengukuran indikator dengan variabel latennya. Pengukuran discriminant validity dinilai berdasarkan pengukuran cross loading dengan konstruk. Selain itu, discriminant validity dapat dilakukan dengan cara membandingkan nilai square root average variance extracted (akar AVE) setiap konstruk dengan korelasi antar konstruk tersebut terhadap konstruk lainnya dalam model. Jika nilai akar AVE suatu konstruk lebih besar dibandingkan dengan nilai korelasi terhadap konstruk lainnya dalam model, maka dapat disimpulkan konstruk tersebut memiliki discriminant validity yang baik. Direkomendasikan nilai akar AVE harus lebih besar 0.50 (Fornell dan Larcker, 1981 dalam Ghozali, 2011, p. 25). Menurut kriteria Fornell-Larcker (1981) nilai-nilai elemen diagonal (warna gelap) lebih besar dari niali-nilai secara vertikal maupun horizontal lainnya. Hal ini merupakan indikasi bahwa instrumen penelitian menunjukkan validitas diskriminan yang tinggi. Reliabilitas individu dapat diukur dengan melihat nilai loading terkait dengan konstruk bersangkutan (Hulland, 1999). Makin tinggi nilai loading berarti makin besar varians yang dapat dijelaskan dibandingkan dengan error varians. Ada dua ukuran yang bisa digunakan yakni melihat Cronbach alpha (> 0.60) dan composite reliability dari Fornell \& Larcker (1981). Inner model atau model struktural dilakukan dengan melihat presentase varian yang dijelaskan yaitu dengan melihat R2 untuk konstruk laten dependen. Stabilitas dari estimasi ini dievaluasi dengan uji t-statistik dan pengaruh positif dan negatif dilihat dari original sample (O) yang didapat lewat prosedur bootstrapping. Evaluasi goodness-of-fit inner model dievaluasi dengan menggunakan R-square untuk variabel laten dependen dengan interpretasi yang sama dengan regresi. R-square mengartikan keragaman konstruk endogen yang mampu dijelaskan oleh konstruk-konstruk eksogen secara serentak (Vinzi, Chin, Henseler dan Wang, 2010). Tabel 4.6 di atas menunjukkan bahwa nilai reliabilitas lebih besar dari 0.60, 
bahkan menggunakan kriteria composite reliability memperlihatkan loading yang lebih besar dibandingkan berdasarkan Cronbach Alpha. Hal ini merupakan indikasi bahwa alat ukur memiliki nilai konsistensi yang tinggi.

\subsection{Uji Fit Model}

Dalam menilai model struktural dengan struktural PLS dapat dilihat dari nilai $R$ Squares untuk setiap variabel laten endogen sebagai kekuatan prediksi dari model struktural. Nilai $R$-Squares merupakan uji goodness of fit model. Perubahan nilai $R$-Squares digunakan untuk menjelaskan pengaruh variabel laten eksogen tertentu terhadap variabel laten endogen, apakah mempunyai pengaruh substantive. Nilai $R$-Squares 0,$67 ; 0,33$; dan 0,19 untuk variabel laten endogen dalam model struktural menunjukkan model kuat, moderat, dan lemah (Chin, 1998 dalam Ghozali, (2011). Hasil dari PLS R-Squares mempresentasikan jumlah variance dari konstruk yang dijelaskan oleh model. Tabel 4.7. di atas memperlihatkan bahwa Nilai $R$-square untuk budaya organisasi adalah sebesar 0,674. Nilai ini menunjukkan bahwa persentase besarnya budaya organisasi yang dapat dijelaskan oleh kepemimpinan adalah sebesar $67.4 \%$. Sementara nilai R-square knowledge sharing sebeesar 0.785 , artinya variabel kepemimpinan mampu menjelaskan knowledge sharing sebesar $78.5 \%$.

\subsection{Pengujian hipotesis}

Hipotesis penelitian dapat diterima jika nilai $\mathrm{t}$ hitung ( $t$-statistic) $>\mathrm{t}$ tabel pada tingkat kesalahan (a) 5\% yaitu 1.96. Nilai T-statistics dapat diketahui dari inner model Tstatistics pada hasil pengolahan data menggunakan PLS.

\begin{tabular}{|l|l|l|l|}
\hline \multicolumn{4}{|c|}{ Tabel 5.1. Nilai Inner Model T-Statistics } \\
\hline & KepTransf & Budaya Org. & KS \\
\hline Kepemimpinan & & 2.756 & 3.869 \\
\hline Budaya Organisasi & & & 2.472 \\
\hline
\end{tabular}

Sumber: Hasil Olah PLS

Berdasarkan Tabel 5.1. di atas nampak bahwa nilai T-statistics inner model menunjukkan bahwa t hitung lebih besar dari t-tabel pada tingkat kesalahan 5\% yaitu 1.96 . Nilai-nilai tersebut seluruhnya lebih besar dari 1.96

Sementara itu Path Coefficient yang dihasilkan menunjukkan korelasi antara variabel laten seperti ditunjukkan oleh tabel berikut.

\begin{tabular}{|l|l|l|l|}
\hline \multicolumn{3}{|c|}{ Tabel 5.2. Nilai Path Coefficient } \\
\hline & Kepemimpinan & Budaya Org. & KS \\
\hline Kepemimpinan & & 0.692 & 0.687 \\
\hline Budaya Organisasi & & & 0.703 \\
\hline
\end{tabular}

Berdasarkan data yang tersaji pada Tabel 5.2. dapat dijelaskan bahwa pengaruh dari kepemimpinan terhadap budaya organisasi sebesar 0.692 dengan nilai T-statistic sebesar 2.756 yang lebih besar dari 1,96. Keadaan ini menunjukkan bahwa kepemimpinan mempunyai pengaruh positif dan signifikan terhadap budaya organisasi. Pengaruh yang dihasilkan oleh kepemimpinan terhadap budaya organisasi adalah positif yang memiliki arti jika pemimpin perusahaan menerapkan kepemimpinan yang seharusnya akan mempengaruhi budaya organisasi dalam perusahaan secara signifikan.

Pengaruh dari kepemimpinan terhadap knowldge sharing. Berdasarkan data yang tersaji pada Tabel 5.2. dapat dijelaskan bahwa pengaruh variabel kepemimpinan terhadap knowledge sharing sebesar 0,687 dengan nilai T-statistic sebesar 3.869 yang lebih besar dari 1,96. Keadaan ini menunjukkan bahwa kepemimpinan mempunyai pengaruh signifikan terhadap knoweldge sharing. Pengaruh yang dihasilkan oleh kepemimpinan terhadap knowledge sharing adalah positif yang memiliki arti jika perusahaan menerapkan 
kepemimpinan maka akan berpengaruh secara signifikan terhadap knowledge sharing. Temuan penelitian ini sejalan dengan hasil penelitian sebelumnya yang dilakukan oleh Politis (2001) yang menemukan bahwa hanya dimensi leadership style yang diajukan Bass (1985) berhubungan positif dengan atribut knowledge sharing, sedangkan lainnya memiliki hubungan negatif. Hal ini berarti bahwa gaya kepemimpinan dengan karakteristik partisipatif yang disertai adanya saling percaya dan hormat terhadap ide dan perasaan bawahan, memiliki hubungan positif dengan atribut knowledge sharing jika dibandingkan dengan gaya kepemimpinan dengan karakteristik task oriented dan autocratic behavior. Temuan penelitian ini juga memperkuat hasil penelitian Crawford (2005) dan Yueh et al. (2010) dengan melakukan penelitian terhadap 300 karyawan di berbagai jenjang manajemen pada beberapa hotel bertaraf internasional di Taiwan. Hasil penelitian menunjukkan bahwa gaya kepemimpinan transformasional memiliki korelasi positif dengan implementasi customer relationship marketing berbasis knowledge, sedangkan gaya kepemimpinan transaksional berkorelasi negatif. Kajian yang sama juga dilakukan oleh Singh (2008) pada perusahaan-perusahaan sofware di India dan menemukan bahwa gaya kepemimpinan consulting dan delegating secara signifikan berpengaruh positif terhadap proses dan praktik knowledge sharing, sementara gaya kepemimpinan directive dan supportive berpengaruh negatif.

Pengaruh dari budaya organisasi terhadap knowledge sharing. Berdasarkan data yang tersaji pada Tabel 5.2. dapat dijelaskan bahwa pengaruh variabel budaya organisasi terhadap knowledge sharing sebesar 0,703 dengan nilai T-statistic sebesar 2.472 yang lebih besar dari 1,96. Keadaan ini menunjukkan bahwa budaya organisasi memiliki pengaruh positif dan signifikan terhadap knowledge sharing. Pengaruh yang dihasilkan oleh budaya organisasi terhadap knowledge sharing adalah positif yang memiliki arti jika di dalam perusahaan terdapat budaya organisasi yang baik maka proses knowledge sharing akan semakin kondusif dan lancar atau tidak mengalami hambatan budaya organisasi. Para ahli mengatakan bahwa budaya organisasi yang baik merupakan jaminan sumber keunggulan bersaing berkelanjutan perusahaan (Collis \& Montgomery, 2008). Budaya organisasi sebagai keyakinan, nilai, norma dan sikap yang mengatur individu bertindak dan berlaku dalam organisasi, adalah salah satu sumber daya nirwujud (intangible resources) yang dimiliki oleh perusahaan (Holsapple \& Joshi, 2000; Yeh et al., 2006; Wong, 2005) untuk mencapai keunggulan bersaing ketika bernilai, langka dan sulit ditiru (Barney, 1986; Klein, 2011). Hasil penelitian ini sejalan dengan peneliti sebelumnya yang mengatakan bahwa budaya organisasi (atau corporate culture) berpengaruh terhadap berbagai aspek knowledge sharing (DeLong \& Fahey, 2000; Bavarsad et al., 2013; Rai, 2011), melainkan juga mempengaruhi keinginan individu dalam organisasi untuk berbagi pengatahuan. Lebih jauh penelitian ini juga memperkuat hasil kajian Shafei et al. (2011) menguji hubungan antara dimensi budaya organisasi Denison (involvement, consistency, adaptability, dan mission) dengan knowledge sharing pada 4 lembaga pemerintah Iran pada tahun 2010. Dengan tingkat pengembalian kuesioner 190 dari 226 diperoleh kesimpulan bahwa terdapat hubungan signifikan positif antara dimensi budaya organisasi dengan unsurunsur proses knowledge sharing. Penelitian serupa dilakukan oleh Allameh et al. (2011) terhadap 156 karyawan perusahaan penyulingan minyak Iran dan menunjukkan bahwa terdapat hubungan yang signifikan antara budaya organisasi, sebagai salah satu faktor kunci, dengan unsur-unsur proses knowledge sharing. 


\section{KESIMPULAN DAN SARAN}

\subsection{Kesimpulan}

1. Di era industri (industrial age) bisnis telah bergeser ke era pengetahuan (knowledge age) dalam berbagai aspek pengelolaan organisasi perusahaan, seperti penggunaan sumber daya sangat tergantung pada tangible assets berupa material dan modal finansial, telah ditinggalkan karena peran kepemilikan dan penguasaan pengetahuan (knowledge) dan modal intelektual (intellectual capital). Demikian halnya dengan pengembangan pengetahuan sumber daya manusia menghasilkan tenaga kerja dengan keterampilan sangat khusus berubah menjadi tenaga kerja dengan pengetahuan lintas disiplin. Tetapi intellectual capital ini tidak akan menjadi sumber daya kompetitif bilamana hanya dikuasai oleh satu atau beberapa orang tertentu dalam organisasi. Dibutuhkan proses berbagi (sharing) dan melalui knowledge sharing, individu berbagi opini, pengalaman dan informasi organisasional dalam organisasi.

2. Leadership merupakan salah satu faktor kunci keberhasilan (enablers atau drivers) penerapan knowledge sharing dalam suatu organisasi. Oleh karenanya manajemen sebaiknya mengutamakan peran leadership dalam knowledge sharing sehingga memberikan dampak kepada penyebaran pengetahuan secara menyeluruh dalam organisasi. Jika pemimpin memberikan contoh bagaimana seharusnya knowledge sharing dikelola, maka semua organ lain dalam organisasi akan mengikuti karena leadership sangat berperan dalam penciptaan dan pengelolaan pengetahuan dalam organisasi, sehingga keunggulan bersaing sebagai tujuan organisasi knowledge sharing dapat dicapai melalui implementasi leadership. Leadership melekat pada individu dalam organisasi untuk menentukan efektivitas implementasi knowledge sharing baik selaku top management yang memberikan contoh kepada seluruh jenjang dalam organisasi, maupun middle management yang menjembatani pola pikir top management dengan pekerja di tingkat bawah (front-line employee).

3. Sebagian besar keberhasilan knowledge sharing berkaitan dengan budaya organisasi dan kerjasama di berbagai tingkat dalam organisasi, sehingga agar sukses dalam memperoleh dan mentransfer pengetahuan, semua dimensi budaya organisasi memegang peran penting agar perusahaan yang telah memiliki sistem knowledge sharing yang komprehensif, tetapi lemah dalam budaya organisasi sebagai faktor pendukung, maka efisiensi knowledge sharing menjadi terbatas. Hasil penelitian ini menunjukkan bahwa budaya organisasi berpengaruh positif dan signifikan terhadap proses knowledge sharing di PDAM Pulau Lombok. Oleh karenanya dibutukan langkah penting sebelum memutuskan penyesuaian tujuan knowledge sharing dengan budaya organisasi, atau melakukan perubahan terhadap culture itu sendiri.

\subsection{Saran}

1. Manajemen PDAM hendaknya terus menggalakkan bagaimana cara memperoleh pengetahuan (knowledge acquisition), mengembangkan dan melakukan transfer pengetahuan (knowledge transfer) secara internal organisasi sehingga terjadi akumulasi pengetahuan. Hal ini untuk jangka panjang akan menjadi intelllectual capital (modal pengetahuan) yang sangat kompetitif terutama dalam menghadapi era 4.0 industrial revolution. Dari sisi pengembangan organisasi perlu dipikirkan sejak awal untuk membentuk struktur organisasi yang di dalamnya terdapat divisi atau bagian Human Capital Management sebagai langkah antisipatif terhadap perkembangan bidang usaha terkait penyediaan air minum. 
2. Diperlukan pemahaman baru tentang definisi kepemimpinan. Bahwa kepemimpinan merupakan tindakan manajerial bagaimana mempengaruhi orang lain dalam mencapai tujuan adalah pemahaman yang berbasis pada sumbaer daya (resource-based leadership). Era sekarang adalah digital dimana akses dan perpindahan pengetahuan begitu cepat sehingga pengetahuan bukan lagi monopoli pimpinan. Perkembangan ini mempengaruhi kalangan ahli dan praktisi dalam memahami konsep kepemimpinan yang beralih ke knowledge-based leadership. Dengan perubahan ini maka makna kepemimpinan bergeser ke bagaimana seorang pemimpin mempengaruhi dan dipengaruhi dalam mencapai tujuan organisasi, termasuk proses knowledge sharing.

3. Manajemen PDAM hendaknya (sekurang-kurangnya) memelihara budaya organisasi yang telah ada sebagai intangible assets perusahaan yang unik terutama budaya trust yang sangat dibutuhkan untuk mendorong aplikasi dan pengembangan pengetahuan dalam organisasi. Oleh karena iklim trust dan keterbukaan merupakan kunci utama knowledge culture dimana pembelajaran tetap sangat bernilai, dihargai dan didukung. Rasa percaya harus tetap ada apakah ketika sebagai pemberi ataupun penerima transfer knowledge karena akan memberikan keyakinan dan rasa aman ketika proses knowledge sharing terjadi.

\section{DAFTAR PUSTAKA}

Alavi, Maryam \& Leidner Dorothy E., 2001, Knowledge Management and Knowledge Management Systems: Conceptual Foundations and Research Issues, Management Information System Quarterly.

Awad, Elias M \& Hasan M. Ghaziri, 2004, Knowledge Management, International Edition, New Jersey.

Barney, J. (1991), Firm resources and sustained competitive advantage, Journal of Management.

Bass, Bernard M., Avolio et al., 2003, Predicting unit performance by assessing transformational and transactional leadership, Journal of Applied Psychology.

Choi, Byounggu et al., 2008, Effects of Knowledge Management strategy on organizational performance: A complementary theory-based approach, The International Journal of Management Science, Omega.

Collis, David J. \& Montgomery, Cynthia A., 2008, Competing on Resources, Harvard Business Review, 140-150.

Crawford, C.B., 2005, Effects of transformational leadership and organizational position on knowledge management, Journal of Knowledge Management.

Davenport, Thomas H., De Long, David W. \& Beers, Michael C., 1998, Successful Knowledge Management Projects, Sloan Management Review, 43-57.

De Tienne, Kristen Bell, Dyer, Gibb, Hoopes, Charlotte \& Harris, Stephen, 2004, Toward a model of effective knowledge management and directions for future research: culture, leadership, and CKOs, J of Lead and Organizational Studies..

Denison, Daniel R. \& Mishra, Aneil K., 1995, Toward a theory of organizational culture and effectiveness, Organization Science, 6 (2), 204-223.

Denison, Daniel R., 1984, Bringing corporate culture to the bottom line, Organizational Dynamics.

Dixion, R. E. (1999), Explaining knowledge sharing the role of team communication styles, job satisfaction, and performance beliefs, Communication Research, 33(2), 115-1

Fey, Carl F. \& Denison, Daniel R., 2003, Organizational culture and effectiveness: Can American theory be applied in Russia ?, Organization Science, 14 (6), 686-706. 
Gold, Andrew H., Malhotra, Arvind, \& Segars, Albert H., 2001, Knowledge Management: Organizational Capabilities Perspective, Journal of Management Information Systems.

Gordon, George G. \& DiTomaso, Nancy, 1992, Predicting corporate performance from organizational culture, Journal of Management Studies, 29 (6), 783-798.

Grant, R. M. (1996), Toward a knowledge-based theory of the firm, Strategic Management Journal, (17) , Winter Special Issue, 109-22.

Grant, Robert M., 2010, Contemporary Strategy Analysis, John Wiley \& Sons, Seventh Edition, UK.

Greenberg, Jerald \& Baron, Robert A., 2008, Behavior In Organizations, Pearson Education International Ninth Edition, New Jersey.

Grover, Varun \& Davenport, Thomas H., 2001, General Perspectives on Knowledge Management: Fostering a Research Agenda, J of Management Information Systems,

Holsapple, C.W. \& Joshi, K.D., 2001, Organizational knowledge resources, Decision Support Systems, 31, 39-54.

Hong, T \& Kuo, L. (1999), Effects of extrinsic and intrinsic motivation on employee knowledge sharing intentions, Journal of Information Science, 33(2), 2007, 135-149.

Hwang, Heungsun \& Takane, Yoshio, 2004, Generalized Structured Component Analysis, Psychometrika, vol. 69, No. 1, 81-89.

Jiang, $\mathrm{Xu} \& \mathrm{Li}, \mathrm{Yu}, 2009$, An empirical investigation of knowledge management and innovative performance: The case of alliances, Research Policy, 38, 358-368.

Kennedy \& Anderson, 2002, Impact of leadership style and emotions on subordinate performance, The Leadership Quarterly, 13, 545-559.

King, S. K., \& Horwitz, I. B. (2001), The effects of team diversity on team outcomes: A metaanalytic review of team demography, Journal of Management, 33(6), 987-1015.

Leibold, Marius; Probst Gilbert \& Gibbert Michael, 2005, Strategic Management in the Knowledge Economy: New Approaches and Business Applications, Germany, Publicis-

Liebowitz, Jay, 1999, Key Ingredients to the Success of an Organization's Knowledge Management Strategy, Knowledge \& Process Management, 6 (1), 37-40.

Luthans, Fred, 2002, Organizational Behavior, Ninth Edition, McGraw-Hill Irwin, NY,

Michalisin, M.D., Smith, R.D., and Kline, D.M., 1997, In Search of Strategic Assets, International Journal of Organizational Analysis.

Miles, R.E. \& C.C. Snow, Organizational Strategy, Structure, and Process, McGraw-Hill,

Morden, Tony, Principles of Strategic Management, Ashgate Publishing Company, 2007, Burlington, VT, USA.

Nandakumar, M.K., Ghobadian, Abby \& O’Regan, Nicholas, 2010, Business-level strategy and performance, Management Decision.

Narver, John C. \& Slater, Stanley, F., 1990, The Effect of Market Orientation on Business Profitability, Journal of Marketing.

Neely, Andy, Richards H., Mills J., Platts K., \& Bourne M., 1997, Designing performance measures: a structured approach, International Journal of Operations \& Production

Nonaka, Ikujiro \& Takeuchi, Hirotaka, 1995, The Knowledge-Creating Company: How Japanese Companies Create the Dynamics of Innovation, Oxford University Press, New

Nonaka, Ikujiro, 2006, Creating Sustainable Competitive Advantage Through Knowledgebased Management, http:/ / www.google.com.Download September 2011.

Nonaka, Ikujiro, Toyama, Ryoko \& Konno, Noboru, 2000, SECI, Ba and leadership: a unified model of dynamic knowledge creation, Long Range Planning, 33, 5-34.

, Permendagri Nomor 2 Tahun 2007.

Porter M.E., “What is Strategy?" Harvard Business Review (November-December 1996): 64 
Rai, Rajnish Kumar, 2011, Knowledge management and organizational culture: a theoretical integrative framework, Journal of Knowledge Management, 15 (5), 779-801.

Sabherwal, Rajiv \& Becerra-Fernandez, Irma, 2003, An Empirical Study of Knowledge Management Processes at Individual, Group, and Organizational Level, Decision Science,

Schein, Edgar H., 2004, Organizational Culture and Leadership, John Wiley \& Sons, Inc., San Fransisco, CA.

Senge, Peter M., 1990, The Fifth Discipline, The Art E Practice of The Learning Organization, Currency Doubleday, New York.

Singh, Sanjay Kumar, 2008, Role of leadership in knowledge management: a study, Journal of Knowledge Management, 12 (4), 3-15.

Tsai, Ming-Tsien \& Li, Yong-Hui, 2007, Knowledge Creation Process in new venture strategy and performance, Journal of Business Research.

Tseng, Shu-Mei, 2010, The correlation between organizational culture and knowledge conversion on corporate finance, Journal of Knowledge Management.

Venkatraman N., 1989, Strategic orientation of business enterprises: the construct, dimensionality, and measurement, Management Science.

Wernerfelt, B. (1984), A resource-based view of the firm, Strategic Management Journal.

Xenikou, Athena \& Simosi, Maria, 2006, Organizational culture and transformational leadership as predictors of business unit performance, J of Managerial Psychology.

Yang, Ching-Chiao, Marlow, Peter, B., \& Lu, Chin-Shan, 2009, Knowledge Management Enablers in liner shipping, Transportation Research Part E. 